\title{
Historical and current predictors of self-reported health status among elderly persons in Barbados
}

\author{
Ian R. Hambleton, ${ }^{1}$ Kadene Clarke, ${ }^{1}$ Hedy L. Broome, ${ }^{2}$ \\ Henry S. Fraser, ${ }^{2,3}$ Farley Brathwaite, ${ }^{4}$ and Anselm J. Hennis ${ }^{2,3}$
}

Suggested citation Hambleton IR, Clarke K, Broome HL, Fraser HS, Brathwaite F, Hennis AJ. Historical and current predictors of self-reported health status among elderly persons in Barbados. Rev Panam Salud Publica. 2005;17(5/6):342-52.

ABSTRACT Objective. To understand the relative contribution of past events and of current experiences as determinants of health status among the elderly in the Caribbean nation of Barbados, in order to help develop timely public health interventions for that population.

Methods. The information for this prevalence study was collected in Barbados between December 1999 and June 2000 as part of the "SABE project," a multicenter survey in seven urban areas of Latin America and the Caribbean that evaluated determinants of health and well-being in elderly populations (persons 60 and older). We used ordinal logistic regression to model determinants of self-reported health status, and we assessed the relative contribution of historical socioeconomic indicators and of three current modifiable predictor groups (current socioeconomic indicators, lifestyle risk factors, and disease indicators), using simple measures of association and model fit.

Results. Historical determinants of health status accounted for $5.2 \%$ of the variation in reported health status, and this was reduced to $2.0 \%$ when mediating current experiences were considered. Current socioeconomic indicators accounted for $4.1 \%$ of the variation in reported health status, lifestyle risk factors for $7.1 \%$, and current disease indicators for $33.5 \%$.

Conclusions. Past socioeconomic experience influenced self-reported health status in elderly Barbadians. Over half of this influence from past events was mediated through current socioeconomic, lifestyle, and disease experiences. Caring for the sick and reducing lifestyle risk factors should be important considerations in the support of the current elderly. In addition, ongoing programs for poverty reduction and increased access to health care and education should be considered as long-term strategies to improve the health of the future elderly.

Key words Health status, aged, socioeconomic factors, Barbados.

1 University of the West Indies, Tropical Medicine Research Institute, Kingston, Jamaica.

2 University of the West Indies, Tropical Medicine Research Institute, Chronic Disease Research Centre, Bridgetown, Barbados. Send correspondence to: Anselm Hennis, Chronic Disease Research Centre, Jemmott's Lane, Bridgetown, Barbados; tele- phone: 246426 6416; fax: 246426 8406; e-mail: ahennis@caribsurf.com

3 University of the West Indies, Cave Hill Campus, School of Clinical Medicine and Research, Bridgetown, Barbados.

4 University of the West Indies, Cave Hill Campus, Faculty of Social Sciences, Bridgetown, Barbados.
The average age of the population in countries around the world continues to rise, reflecting the concurrent declines in fertility and adult mortality (1). Population aging represents a public health success story, but it simulta- 
neously creates new economic and social challenges. The elderly experience disproportionate levels of chronic disease and disability, which reduces their quality of life and increases the demand for health care and social services. In recent decades the speed of population aging in many less-developed countries has been dramatic (2), and in these countries this aging is likely to exceed the wealth accumulation needed to cope with the increased economic burden on society (3).

Public health programs to meet the challenges of aging focus on the concept of "active aging" (4), which promotes the optimization of health; participation of the elderly in the socioeconomic, cultural, and spiritual activities of the community; and social, financial, and physical security as the central tenets for an improved quality of life. As one strand of this public health response, "health" refers to mental and social well-being as well as physical aspects (5). Self-reported health status has been widely used in censuses, surveys, and observational studies as a succinct measure that may encompass these subjective concepts $(6,7)$. Determinants of self-reported health status have been widely studied (8-10), and this health outcome has been shown to predict future morbidity and mortality (11-13).

Research should help to inform and focus public health policy. Until a relatively short time ago, published evidence on the health of the elderly in developing nations had been lacking. However, recently completed surveys now provide a wealth of data on health and aging in regions with rapidly aging populations (14). The quantity of collected information available to the analyst can be overwhelming, and it is important that public health questions be answered using appropriate analysis strategies. Although univariate examination of possible health predictors can be insightful, methods to account for associations between predictors are generally preferred. However, widely available automation of variable selection strategies has led to statistical significance becoming synonymous with practical importance, which is not al-

FIGURE 1. Pathways among socioeconomic indicators (SEIs), lifestyle risk factors, and disease indicators and self-repaorted health, as assessed in study of historical and current predictors of self-reported health status in elderly persons, Barbados, 1999-2000

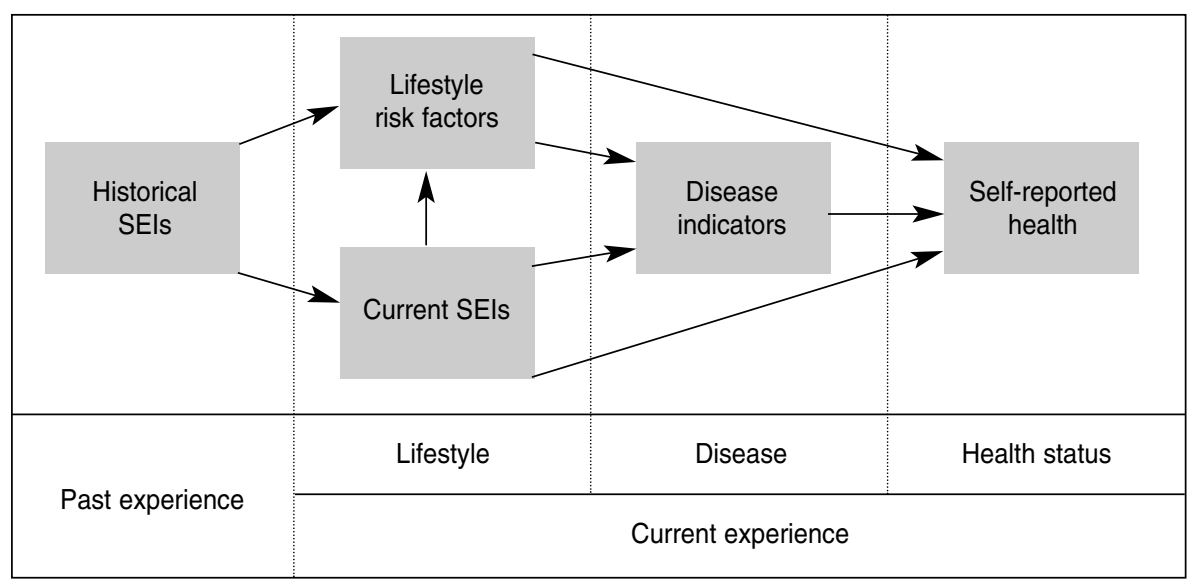

ways appropriate. Rather than automated selection of health predictors, we have developed a conceptual model of health status predictors that identifies distinct life phases, and we have examined possible predictors within this theoretical framework. From a public health perspective, we must be certain that changes in behavior are possible, and that these changes can improve health. This question is particularly relevant for persons who are now elderly. They have experienced the majority of their life course, and their current health may be decisively informed by past events.

In this study we investigated selected social and clinical determinants of self-reported health status among elderly persons in the Caribbean nation of Barbados. Below we first present our conceptual model of health status predictors, and then we examine the relative contribution of historical and modifiable factors on selfperceived health status.

\section{Conceptual model}

Many studies have linked socioeconomic indicators with health (15-18). In addition, the causal order of various socioeconomic indicators (SEIs) as determinants of health has been dis- cussed $(19,20)$, with attention focusing on education, occupation, and income as key indicators. Education is generally experienced first in the life course, and it influences income through its direct effect on occupation. In our Barbados sample all three of those indicators were interrelated, with correlation coefficients ranging from 0.34 to 0.44 . As these simple relationships highlight, considering each indicator on its own will ignore interactions with other factors. These interactions may in turn reflect pathways through a person's life course (21).

More generally, we might classify possible predictors of self-reported health into four distinct groups: one group of past events (historical SEIs) and three groups summarizing ongoing experience (lifestyle risk factors, current SEIs, and disease indicators) (Figure 1). Historical SEIs refer to socioeconomic experiences from earlier in the life course. Although these past experiences may affect health reporting through their influence on intermediate conditions, as historical events they cannot directly modify health status and cannot be modified by current public health policy. Current SEIs reflect current socioeconomic conditions. Modification is feasible, although in many resource-poor situations it may be impractical. Current 
risk factors reflect individual lifestyle choices and are the most readily altered influences on health. Disease indicators are just one aspect of selfreported health, but because they often reflect recent experience they are likely to be strong determinants of individuals' health perceptions.

Proactive public health intervention to promote the agenda of "active aging" would focus on readily modifiable features of people's current experience (lifestyle risk factors and, to some extent, current SEIs). The success of such intervention may partly depend on to what extent past experience shapes individuals' perceptions of their current health status.

\section{Aims of this study}

Our main aim was to examine the socioeconomic and lifestyle determinants of self-reported health status among elderly men and women in Barbados. In particular, we wanted to examine the strength of selected determinants from each predictor group, the strength of associations between the four predictor groups, and the extent to which earlier life course effects on health are mediated through more recent experiences.

\section{DATA AND METHODS}

\section{Data}

The Barbados study is part of a cross-sectional survey evaluating determinants of health and well-being in Latin America and the Caribbean (Salud, Bienestar y Envejecimiento en América Latina y el Caribe (Health, WellBeing, and Aging in Latin America and the Caribbean), known as the "SABE project") (22). SABE consisted of a cross-sectional survey of people born in 1939 or earlier (60 years or older in 1999) from seven cities in Latin America and the Caribbean, including Bridgetown, Barbados (14). The study design stipulated a minimum sample size of 1500 respondents from each city. The Bridgetown survey, which

TABLE 1. Potential determinants of self-reported health status, study of historical and current predictors of self-reported health status in elderly persons, Barbados, 1999-2000

\begin{tabular}{|c|c|}
\hline Predictor group & Individual predictors in each predictor group \\
\hline Historical socioeconomic indicators & $\begin{array}{l}\text { Education, occupation, childhood economic situation, } \\
\text { childhood nutrition, childhood health, number of childhood } \\
\text { diseases }\end{array}$ \\
\hline Current socioeconomic indicators & $\begin{array}{l}\text { Income, financial means, household crowding, living alone, } \\
\text { currently married, number of people in the household, number } \\
\text { of children living outside household, number of siblings living } \\
\text { outside household, number of other family and friends living } \\
\text { outside household }\end{array}$ \\
\hline Current lifestyle risk factors & $\begin{array}{l}\text { Body mass index, waist circumference, categories of disease } \\
\text { risk, nutrition, smoking, exercise }\end{array}$ \\
\hline Disease indicators & $\begin{array}{l}\text { Number of illnesses, }{ }^{a} \text { number of symptoms, }{ }^{b} \text { Geriatric } \\
\text { Depression Scale score, number of nights in hospital in } \\
\text { 4-month period, number of medical contacts in 4-month period }\end{array}$ \\
\hline $\begin{array}{l}\text { a IIInesses included hypertension, diabete } \\
\text { and arthritis. } \\
\text { b Symptoms included chest pain, shortnes } \\
\text { in the feet or ankles, persistent dizziness } \\
\text { vomiting, and persistent thirst or excessi }\end{array}$ & $\begin{array}{l}\text { er, chronic lung disease, coronary heart disease, cerebrovascular accident, } \\
\text { ath, back pain, severe fatigue or tiredness, joint problems, persistent swelling } \\
\text { tent headaches, persistent wheezing, cough or phlegm, persistent nausea or } \\
\text { ating. }\end{array}$ \\
\hline
\end{tabular}

was conducted between December 1999 and June 2000, identified 1878 eligible persons, and it collected completed information on 1508 of them (an overall response rate of $80 \%$ ). Response varied by age and gender, from a low of $73 \%$ among men between 60 and 64 to a high of $88 \%$ among women aged 85 and over. Weights were applied to all analyses to account for the sampling design and nonresponse. Sixty-five respondents did not pass a preliminary cognitive test and were assigned a proxy respondent to provide help with questionnaire responses. Because of the subjective nature of selfreported health, we excluded these participants from the current analysis.

Our selection of potential determinants of self-reported health status for each of the four predictor groups is presented in Table 1.

\section{Historical socioeconomic indicators}

We considered six historical SEIs as potential predictors of self-reported health status. We classified education as elementary, secondary, or higher, with the third category consisting of any post-secondary or university training. We defined occupation as the job in which a participant worked for the majority of his or her life, or the most recent principal employment. We first classified occupation according to the International Standard Classification of Occupations (ISCO-88), which is a classification system produced by the International Labor Organization. We then grouped the occupations into three broader classifications: professionals (managers, senior officials, and professionals), semiprofessionals (technicians, office workers, and skilled laborers), and nonprofessionals (service and sales workers, farmers, unskilled workers, and homemakers).

We recorded information on aspects of the participants' childhood experiences by asking three questions about the first 15 years of their life: whether their economic situation was good, average, or poor; whether their health was excellent, good, or poor; and whether there was a time when they didn't have enough to eat and were hungry. We also asked participants to list any diseases they had had as a child, and we used a list of common childhood conditions to aid recollection. 


\section{Current socioeconomic indicators}

We calculated monthly income as the sum of the current salary (for employed individuals) and all other sources of income such as pensions and retirement benefits. We recorded self-reported financial means by asking participants if they had enough money to meet daily living expenses. We calculated household room density as the number of people in a household divided by the number of rooms, excluding the kitchen and bathroom. Social networks have been reported as an influence on health $(23,24)$. We collected basic information on social networks by recording whether the participant was married, the number of people living in the household, the number of children living outside of the household, the number of siblings living outside of the household, the number of other family and friends living outside of the household, and whether the participant received assistance from any institutions in the community (such as social services, senior citizen's center, or church group). Household members, children, and siblings did not need to give or receive assistance in order to be considered part of the respondent's social network.

\section{Lifestyle risk factors}

To classify adiposity, we used body mass index (BMI) and waist circumference. Using BMI, we defined participants as normal $\left(\mathrm{BMI}<25 \mathrm{~kg} / \mathrm{m}^{2}\right)$, overweight $\left(25 \leq \mathrm{BMI}<30 \mathrm{~kg} / \mathrm{m}^{2}\right)$, or obese (BMI $\left.\geq 30 \mathrm{~kg} / \mathrm{m}^{2}\right)$. Waist circumference is an approximate index of intra-abdominal fat mass and total body fat, and it may be a risk factor for cardiovascular and other chronic diseases. We classified participants as high risk for metabolic complications if they were above recommended gender-specific thresholds (men $\geq 102$ $\mathrm{cm}$ and women $\geq 88 \mathrm{~cm}$ ) (25). We also calculated an index of disease risk relative to normal weight and waist circumference in five categories: normal, increased, high, very high, and extremely high (26). We recorded infor- mation on exercise, smoking, and nutrition. We asked participants whether they had exercised or participated in vigorous physical activity three or more times a week over the past 12 months, if they were current or past smokers, and whether they considered themselves well nourished.

\section{Disease indicators}

For this study we summarized detailed disease information to create four indicators of current disease status: the number of illnesses experienced, the number of disease symptoms in the previous 12 months, the number of nights spent in the hospital in the previous 4 months, and the number of times medical care was sought in the previous 4 months. The list of illnesses consisted of: high blood pressure/hypertension, diabetes, malignant tumor (excluding minor skin cancers), chronic lung disease, cardiac disease, stroke, and arthritis. We also used the 15-item Geriatric Depression Scale (GDS) to measure depression (27). During the GDS tabulations we categorized a GDS score of more than 5 to indicate depression, and during all modeling we used the quantitative GDS scores.

\section{Self-reported health status}

We rated self-reported health status on a five-point scale: poor, fair, good, very good, and excellent. Because of low responses in the extreme categories, we modeled self-reported health status in three categories: poor or fair, good, and very good or excellent.

\section{Statistical methods}

We were interested in the individual and joint effects of variables from each predictor group (historical SEIs, current SEIs, lifestyle risk factors, disease indicators) on self-reported health status, and we used ordinal logistic regression at all times. This technique is an extension of logistic regression for an outcome with three or more ordered categories (in our case we used three categories of improving health status: poor or fair, good, and very good or excellent).

We addressed our goals in two stages. In stage one, we modeled each of the four predictor groups separately. We added statistically important terms to each model one at a time, using a manual stepwise technique, after adjusting for the confounding effects of age and gender. The results of each of the four models are presented as odds ratios (ORs) with associated 95\% confidence intervals (CIs). We examined the statistical importance of each additional predictor using a Wald test, using a lenient model inclusion criterion of $10 \%$ significance. This criterion allowed a number of weakly predictive terms to contribute to stage two of the analysis. We assessed the pairwise associations between our four models by obtaining predicted probabilities of self-reported health status, and correlating these predictions.

In stage two we examined the joint effect of the four predictor groups by adding all important predictor terms into a single model. We built this model by first including all important historical SEIs, then adding, in three steps, all important terms from current SEIs, from lifestyle risk factors, and from disease indicators. After each addition of a predictor group, we recorded a simple measure of the extra variation explained by the additional important terms. We were interested in how the amount of information explained by the model changed when further prediction groups were added. We used Stata version 8 software for all analyses (28).

\section{RESULTS}

\section{Distribution of historical socioeconomic indicators}

We present the distributions of the historical SEIs in Table 2. The majority of the participants reported nonprofessional occupations. There were gender differences in occupation, with a 
TABLE 2. Distribution (\%) of historical socioeconomic indicators among 1443 elderly persons in study of historical and current predictors of self-reported health status, Barbados, 1999-2000

\begin{tabular}{|c|c|c|c|}
\hline Indicator & $\begin{array}{l}\text { Response rate } \\
(\%)\end{array}$ & $\begin{array}{l}\text { Women (\%) } \\
(n=879)\end{array}$ & $\begin{array}{l}\text { Men }(\%) \\
(n=564)\end{array}$ \\
\hline Occupation & 98.1 & & \\
\hline Nonprofessionals & & 76 & 55 \\
\hline Semiprofessionals & & 15 & 27 \\
\hline Professionals & & 10 & 18 \\
\hline Education & 98.8 & & \\
\hline Basic & & 77 & 74 \\
\hline Secondary & & 17 & 17 \\
\hline Higher & & 6 & 9 \\
\hline Childhood economic situation & 98.7 & & \\
\hline Poor & & 33 & 44 \\
\hline Average & & 48 & 39 \\
\hline Good & & 19 & 17 \\
\hline Childhood nutrition & 97.5 & & \\
\hline Not hungry & & 86 & 79 \\
\hline Hungry & & 14 & 21 \\
\hline Childhood health & 99.7 & & \\
\hline Below excellent & & 51 & 42 \\
\hline Excellent & & 49 & 58 \\
\hline Number of childhood diseases & 100 & & \\
\hline $0-2$ & & 48 & 56 \\
\hline 3 or more & & 52 & 44 \\
\hline
\end{tabular}

greater proportion of women classified as nonprofessionals. Although men reported a less favorable economic and nutritional situation in childhood, they also reported better health and fewer diseases.

\section{Distribution of current socioeconomic indicators}

We present the distributions of the current SEIs in Table 3. Self-reported income was disclosed by 1079 participants (a response rate of 75\%). We imputed unreported income using an iterative regression algorithm (29), using age, gender, financial means, education, and occupation as income predictors. The imputed income distribution included a larger proportion of "high-earners," suggesting that the well-paid were more reticent about divulging income details. The median reported annual income of US\$ 3132 (interquartile range of US\$ 2088 to US\$ 6 096) was less than the gross national income per capita of US\$ 9750 pend on immediate family members for social contact and support.

\section{Lifestyle risk factors}

We present the distributions of the lifestyle risk factors in Table 4 . Women had a higher mean BMI value $\left(28.2 \mathrm{~kg} / \mathrm{m}^{2}\right)$ than did men $(25.3$ $\left.\mathrm{kg} / \mathrm{m}^{2}\right)$, and a higher proportion of the women $(32 \%)$ were obese than were men $(12 \%)$. Based on waist circumference cutpoints, many more women were at high risk of chronic disease (women 63\%, men 15\%). Almost all the participants considered themselves well nourished, only a small minority continued to smoke (women $1 \%$, men $14 \%$ ), and just under half reported regular exercise (women $42 \%$, men $49 \%$ ).

\section{Disease indicators and health status}

Table 5 shows the distributions of the disease indicators. In comparison to the men, the women reported both a higher average number of illnesses (1.6 vs. 1.1) and a higher mean number of disease symptoms (1.6 vs. 1.1). Only $3 \%$ of the women and $4 \%$ of the men reported spending one or more nights in the hospital in the previous four months, and $77 \%$ of the women and $61 \%$ of the men reported making at least one visit to a doctor over the same period. Similar numbers of men and women were depressed (5\% of women, $6 \%$ of men), according to a standard GDS cutpoint for identifying depression (GDS > 5). Men reported better health: $21 \%$ of the men and $13 \%$ of the women reported very good or excellent health, and $52 \%$ of the women and $41 \%$ of the men reported poor or fair health. networks indicated that just over $20 \%$ of participants were living alone, twothirds of women and one-third of men were unmarried, $20 \%$ of participants were without children, $25 \%$ were without living siblings, $90 \%$ did not report other relatives and friends, and 95\% received no assistance from community sources. These data suggest that elderly Barbadians primarily de-

\section{Individual regressions}

We present the effect of historical SEIs on health status in Table 6. For historical SEIs, the odds of reporting better health status was higher among participants employed as profession- 
TABLE 3. Distribution (\%) of current socioeconomic indicators among 1443 elderly persons in study of historical and current predictors of self-reported health status, Barbados, 1999-2000

\begin{tabular}{|c|c|c|c|}
\hline Indicator & $\begin{array}{l}\text { Response rate } \\
(\%)\end{array}$ & $\begin{array}{l}\text { Women (\%) } \\
(n=879)\end{array}$ & $\begin{array}{l}\text { Men (\%) } \\
(n=564)\end{array}$ \\
\hline Self-reported monthly income (US\$) & 74.8 & & \\
\hline Less than 175 & & 49 & 29 \\
\hline 175 to less than 350 & & 27 & 27 \\
\hline 350 or more & & 24 & 47 \\
\hline Imputed monthly income (US\$) & 100 & & \\
\hline Less than 175 & & 40 & 21 \\
\hline 175 to less than 350 & & 34 & 29 \\
\hline 350 or more & & 27 & 50 \\
\hline Financial means ${ }^{a}$ & 93.0 & & \\
\hline Inadequate & & 65 & 56 \\
\hline Adequate & & 35 & 44 \\
\hline Crowding ${ }^{b}$ & 99.6 & & \\
\hline Less than 0.4 & & 41 & 40 \\
\hline 0.4 to less than 0.6 & & 31 & 30 \\
\hline 0.6 and higher & & 28 & 31 \\
\hline Living alone & 100 & & \\
\hline Yes & & 21 & 22 \\
\hline No & & 79 & 78 \\
\hline Currently married & 99.8 & & \\
\hline No & & 67 & 39 \\
\hline Yes & & 33 & 61 \\
\hline Number of people in household & 100 & & \\
\hline 0 & & 21 & 22 \\
\hline $1-2$ & & 54 & 53 \\
\hline 3 or more & & 26 & 25 \\
\hline Number of children living outside the household & 100 & & \\
\hline 0 & & 24 & 18 \\
\hline $1-2$ & & 32 & 30 \\
\hline 3 or more & & 45 & 52 \\
\hline Number of siblings living outside the household & 100 & & \\
\hline 0 & & 25 & 23 \\
\hline $1-2$ & & 38 & 34 \\
\hline 3 or more & & 37 & 42 \\
\hline Other relatives and friends living outside the household & 100 & & \\
\hline 0 & & 90 & 94 \\
\hline $1-2$ & & 9 & 6 \\
\hline 3 or more & & 1 & 0 \\
\hline
\end{tabular}

${ }^{a}$ Financial means was assessed by asking participants if they had enough money to meet daily living expenses.

${ }^{b}$ Crowding was calculated as the number of people living in the household divided by the number of rooms in the house (excluding the kitchen and bathroom).

als, those with higher education, and those reporting a good economic situation and excellent health during childhood.

Based on current SEIs, the odds of reporting better health status was higher among participants who reported adequate finances to meet daily needs (Table 7). The effect of support networks was mixed, with better health status reported among participants with more siblings, but margin- ally worse health status reported as the number of people in the household increased.

We present the effect of lifestyle risk factors on health status in Table 8 . The odds of reporting better health status was lower among obese participants, among the undernourished, and among those who did not exercise regularly. Smoking offered a contradictory result, with current smokers reporting better health than nonsmokers.
This smoking effect was only seen in women (women, $\mathrm{OR}=2.62 ; 95 \% \mathrm{CI}$, 1.18 to 5.73 , vs. men, $\mathrm{OR}=1.44,95 \% \mathrm{CI}$, 0.85 to 2.85 ), but only $1 \%$ of the women were current smokers.

The effect of disease indicators on health status is shown in Table 9. The odds of reporting better health status was lower among participants reporting more illness, more disease symptoms, and higher scores on the Geriatric Depression Scale.

Predicted probabilities from the four models showed strong and statistically important correlations with each other ( $P<0.001$ in all cases). These correlations attenuated as we compared regressions from predictor groups further apart on the pathway outlined in Figure 1, so that the correlation of the historical SEIs regression with the current SEIs regression was $0.64(95 \% \mathrm{CI}$, 0.61 to 0.68$)$, with the lifestyle regression was 0.55 (95\% CI, 0.51 to 0.59 ), and with the disease regression was 0.32 (95\% CI, 0.27 to 0.38 ), and so on (Figure 2).

In Table 10 we present the amount of variation in reported health status explained by a single model, using the important predictors from each of the four predictor groups. In this table there are three columns reporting the variation in the data that can be explained by the predictor groups included in the model. "Model variation" reports the variation explained by all predictor groups in the model, after adjusting for age and sex. "Common variation" reports the difference in variation between single-predictorgroup models and those models containing more than one predictor group, and is interpreted as the variation that can be jointly ascribed to all predictor groups in the model. For the "Historical SEI + Current SEI" model, the common variation is: Historical SEI model variation + Current SEI model variation - (Historical SEI + Current SEI) model variation, or $5.2 \%+4.1-7.9 \%=$ $1.4 \%$, and so on. "Historical variation" is the variation explained by the historical SEI predictor group alone, after all other terms in the model have been added. In univariate models, age and gender accounted, respectively, for 
TABLE 4. Distribution (\%) of current lifestyle risk factors among 1443 elderly persons in study of historical and current predictors of self-reported health status, Barbados, 1999-2000

\begin{tabular}{|c|c|c|c|}
\hline Risk factor & $\begin{array}{c}\text { Response rate } \\
(\%)\end{array}$ & $\begin{array}{l}\text { Women }(\%) \\
(n=879)\end{array}$ & $\begin{array}{l}\text { Men (\%) } \\
(n=564)\end{array}$ \\
\hline Body mass index & 95.4 & & \\
\hline Normal & & 36 & 57 \\
\hline Overweight & & 32 & 31 \\
\hline Obese & & 32 & 12 \\
\hline Waist circumference & 98.5 & & \\
\hline Low risk & & 37 & 85 \\
\hline High risk & & 63 & 15 \\
\hline Disease risk ${ }^{\mathrm{a}}$ & 95.3 & & \\
\hline Normal & & 36 & 57 \\
\hline Increased & & 9 & 24 \\
\hline High & & 24 & 10 \\
\hline Very/Extremely high & & 31 & 9 \\
\hline Nutrition & 98.1 & & \\
\hline Well nourished & & 97 & 97 \\
\hline Not well nourished & & 3 & 3 \\
\hline Smoking & 99.9 & & \\
\hline Never smoked & & 91 & 47 \\
\hline Ex-smoker & & 8 & 39 \\
\hline Current smoker & & 1 & 14 \\
\hline Exercise & 99.8 & & \\
\hline Yes & & 42 & 49 \\
\hline No & & 58 & 51 \\
\hline
\end{tabular}

TABLE 5. Distribution (\%) of self-reported health status and disease indicators among 1443 elderly persons in study of historical and current predictors of self-reported health status, Barbados, 1999-2000

\begin{tabular}{|c|c|c|c|}
\hline Health status/Disease indicator & $\begin{array}{c}\text { Response rate } \\
(\%)\end{array}$ & $\begin{array}{l}\text { Women }(\%) \\
(n=879)\end{array}$ & $\begin{array}{l}\text { Men (\%) } \\
(n=564)\end{array}$ \\
\hline Health status & 99.7 & & \\
\hline Poor & & 5 & 4 \\
\hline Fair & & 47 & 37 \\
\hline Good & & 35 & 38 \\
\hline Very good & & 10 & 15 \\
\hline Excellent & & 3 & 6 \\
\hline Number of illnesses & 100 & & \\
\hline 0 & & 17 & 34 \\
\hline $1-2$ & & 64 & 57 \\
\hline 3 or more & & 19 & 9 \\
\hline Geriatric Depression Scale & 100 & & \\
\hline Not depressed (GDS $\leq 5)$ & & 95 & 94 \\
\hline Depressed $(G D>5)$ & & 5 & 6 \\
\hline Number of symptoms & 100 & & \\
\hline 0 & & 31 & 50 \\
\hline $1-2$ & & 44 & 39 \\
\hline 3 or more & & 25 & 11 \\
\hline Nights in hospital in 4-month period & 99.4 & & \\
\hline 0 & & 97 & 96 \\
\hline $1-2$ & & 1 & 2 \\
\hline 3 or more & & 2 & 2 \\
\hline Number of medical contacts in 4-month period & 98.8 & & \\
\hline 0 & & 24 & 39 \\
\hline $1-2$ & & 70 & 54 \\
\hline 3 or more & & 07 & 07 \\
\hline
\end{tabular}

$6.1 \%$ and $3.1 \%$ of variation in health status reporting, and we included these confounders in all models.

After adjusting for age and sex, historical SEIs explained an additional $5.2 \%$ of total variation, which compared to $4.1 \%$ from current SEIs, $7.1 \%$ from lifestyle risk factors, and $33.6 \%$ from disease indicators. As other predictor groups are added to the model, the percentage of the variation explained by historical predictors alone decreases, indicating that health status information contained in the historical SEIs was mediated through current predictors. The unique information explained by historical SEIs fell to $3.8 \%$ using current SEIs, $4.0 \%$ using lifestyle risk factors, $2.7 \%$ using disease indicators, and $2.0 \%$ using all other predictor groups together. This suggests that in Barbadian participants, over $60 \%$ of historical SEI information was mediated through current socioeconomic, lifestyle, and disease determinants of self-reported health.

\section{DISCUSSION}

When persons answer questions about their health, they draw on a wealth of past and current experiences that shape their responses. The simple Likert scale of self-perceived health status belies the breadth of information it contains, and it is not surprising that it can be adequately modeled using alternative groups of predictors. This presents a challenge for the analyst who is looking to develop a predictive model of this health outcome. Through repeated analyses, the classic socioeconomic indicators of education, occupation, and income have emerged as robust predictors of current health in adults (31-33). Among the elderly, education, occupation, and other socioeconomic determinants represent past experiences. These historical events are likely to have a smaller effect on health status over time, and any predictive effect that remains will be partly mediated through current lifestyle and disease experience. Although this may mean that historical SEIs are statistically insignificant in a single model of 
TABLE 6. The effect of selected historical socioeconomic indicators on better self-reported health status among 1147 elderly persons in study of historical and current predictors of self-reported health status, Barbados, 1999-2000

\begin{tabular}{llll}
\hline Historical socioeconomic indicator & $\mathrm{OR}^{\mathrm{a}}$ & $95 \% \mathrm{Cl}^{\mathrm{b}}$ & $P$ \\
\hline $\begin{array}{l}\text { Occupation } \\
\quad \text { Nonprofessional }\end{array}$ & & & \\
$\quad$ Semiprofessional & 1.00 & 0.79 to 1.47 & 0.64 \\
$\quad$ Professional & 1.08 & 1.03 to 2.34 & 0.04 \\
$\quad$ Education & 1.55 & & \\
$\quad$ Basic & 1.00 & & \\
$\quad$ Secondary & 1.12 & 0.78 to 1.59 & 0.54 \\
$\quad$ Higher & 1.50 & 0.94 to 2.40 & 0.09 \\
Childhood economic situation & & & \\
$\quad$ Poor & 1.00 & & 0.97 \\
$\quad$ Average & 1.00 & 0.77 to 1.32 & 0.01 \\
$\quad$ Good & 1.67 & 1.15 to 2.42 & \\
$\quad$ Childhood health & & \\
$\quad$ Below excellent & 1.00 & 1.15 to 1.90 & 0.002 \\
$\quad$ Excellent & 1.48 & & \\
\hline
\end{tabular}

${ }^{a} \mathrm{OR}=$ odds ratio.

b $95 \% \mathrm{Cl}=95 \%$ confidence interval.

TABLE 7. The effect of selected current socioeconomic indicators on better self-reported health status among 1147 elderly persons in study of historical and current predictors of self-reported health status, Barbados, 1999-2000

\begin{tabular}{llll}
\hline Current socioeconomic indicator & $\mathrm{OR}^{\mathrm{a}}$ & $95 \% \mathrm{Cl}^{\mathrm{b}}$ & $P$ \\
\hline Financial means & & & \\
$\quad$ Inadequate & 1.00 & & 0.001 \\
$\quad$ Adequate & 1.51 & 1.17 to 1.94 & 0.03 \\
Number of people in household & 0.92 & 0.85 to 0.99 & 0.03 \\
Number of siblings living outside the household & 1.06 & 1.01 to 1.12 & 0.08 \\
Others living outside the household & 0.81 & 0.64 to 1.03 & \\
\hline
\end{tabular}

a $\mathrm{OR}=$ odds ratio.

b $95 \% \mathrm{Cl}=95 \%$ confidence interval.

TABLE 8. The effect of selected current disease mediators on better self-reported health status among 1147 elderly persons in study of historical and current predictors of selfreported health status, Barbados, 1999-2000

\begin{tabular}{|c|c|c|c|}
\hline Disease mediator & $\mathrm{OR}^{\mathrm{a}}$ & $95 \% \mathrm{Cl}^{\mathrm{b}}$ & $P$ \\
\hline \multicolumn{4}{|l|}{ Body mass index } \\
\hline Normal & 1.00 & & \\
\hline Overweight & 0.81 & 0.61 to 1.08 & 0.14 \\
\hline Obese & 0.51 & 0.37 to 0.71 & $<0.001$ \\
\hline \multicolumn{4}{|l|}{ Nutrition } \\
\hline Well nourished & 1.00 & & \\
\hline Not well nourished & 0.45 & 0.20 to 1.03 & 0.06 \\
\hline \multicolumn{4}{|l|}{ Smoking } \\
\hline Never smoked & 1.00 & & \\
\hline Ex-smoker & 1.01 & 0.73 to 1.40 & 0.94 \\
\hline Current smoker & 1.66 & 1.00 to 2.74 & 0.05 \\
\hline \multicolumn{4}{|l|}{ Exercise } \\
\hline Yes & 1.00 & & \\
\hline No & 0.59 & 0.46 to 0.75 & $<0.001$ \\
\hline
\end{tabular}

health status in the elderly, it does not follow that they are conceptually unimportant. This introduces a clear time dimension to this cross-sectional study, which is rarely considered and which requires careful modeling. We have developed a conceptual framework for our analysis, and have modeled health status within this framework in an attempt to identify pertinent predictors within specific predictor groups, and to then assess the relative strength of these predictor groups, and the quantity of historical information that is mediated through current signals.

We confirm the expected associations of better education, professional occupation, and better childhood economic situation and health with improved health status in the elderly. Historical predictors explained 5.2\% of variation in reported health status, but that fell to $2.0 \%$ (a decline of over $60 \%$ ) after adjusting for current SEI, lifestyle, and disease predictors.

Current SEI, lifestyle, and disease predictors of health status broadly followed convention, with the exception of female current smokers, who reported better health than nonsmokers. This seemingly anomalous result may reflect a bias among the group of surviving female smokers, and our inability to explain this result is the major drawback of such crosssectional work. Indicators of disease dominated the prediction of health status, suggesting that while this single measure of health may summarize a complex health "trait," the participants' health perceptions were heavily influenced by their disease experience. Quality-of-life (QoL) tools can provide additional insights into health perceptions, but with increased survey costs. A QoL tool investigating active aging has recently been suggested and examined $(34,35)$.

\section{Study limitations}

Our survey is cross-sectional, and so causal inference is not possible. Many of our findings are intuitive and confirmatory, and a few appear to be con- 
TABLE 9. The effect of selected current disease indicators on better self-reported health status among 1147 elderly persons in study of historical and current predictors of selfreported health status, Barbados, 1999-2000

\begin{tabular}{llll}
\hline \multicolumn{1}{c}{ Disease indicator } & $\mathrm{OR}^{\mathrm{a}}$ & $95 \% \mathrm{Cl}^{\mathrm{b}}$ & $P$ \\
\hline Number of illnesses & 0.55 & 0.48 to 0.64 & $<0.001$ \\
Signs of illness & 0.71 & 0.64 to 0.79 & $<0.001$ \\
Geriatric Depression Scale & 0.85 & 0.78 to 0.94 & $<0.001$ \\
\hline
\end{tabular}

a $\mathrm{OR}=$ odds ratio.

b $95 \% \mathrm{Cl}=95 \%$ confidence interval.

FIGURE 2. Pairwise correlation (with $95 \%$ confidence interval $(\mathrm{Cl})$ ) of regression predictions from regressions using four prediction groups: historical socioeconomic indicators $(H)$, current socioeconomic indicators (C), lifestyle risk factors (L), and disease indicators (D), in study of historical and current predictors of self-reported health status, Barbados, 1999-2000

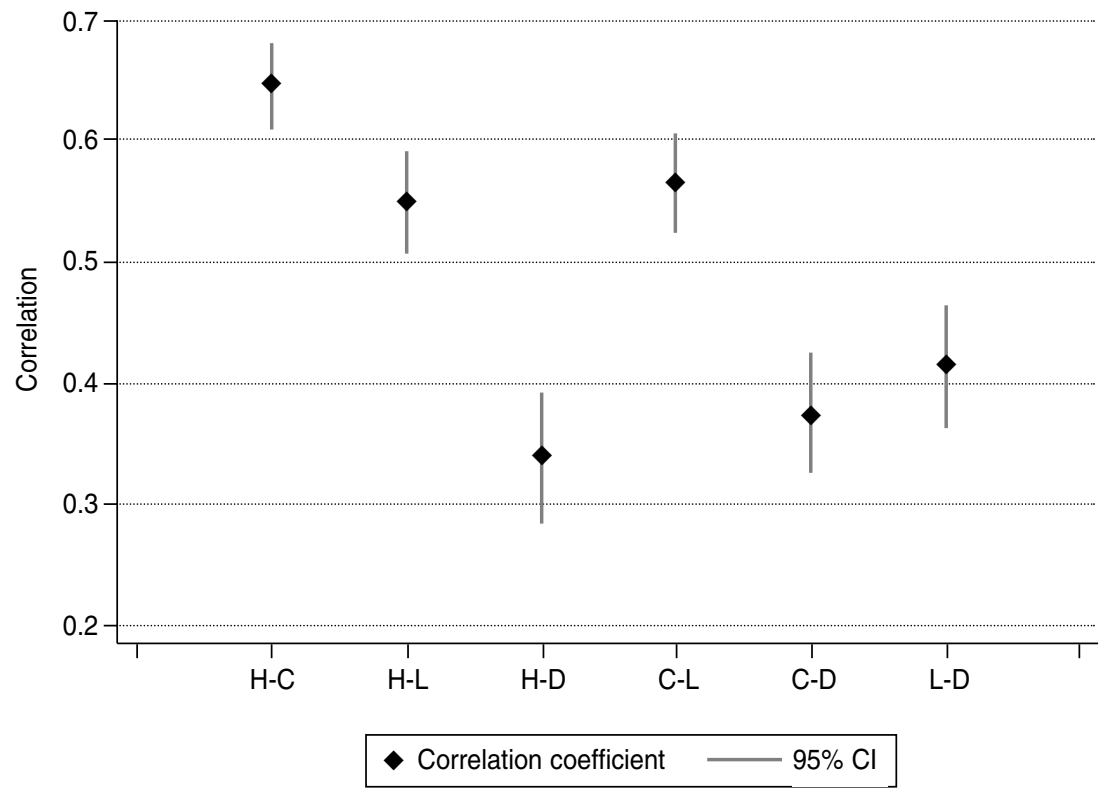

tradictory, with explanations that can only be considered speculative.

Our conceptual model was designed to guide the modeling process and is rather simplistic. In particular, the distinction between historical and current health predictors is not clear-cut: Income and disease indicators are two important variables that have both historical and current components. Moreover, the relative importance of our four predictor groups is based fundamentally on identifying all important potential determinants of health sta- tus. As with most observational work, it is unlikely that we have accounted for all important determinants of health status. The possibility of omitted predictors means that we cannot allocate absolute importance to our predictor groups. That is, the variance explained by each group serves only as a general guide. There are different numbers of predictors in each predictor group, which complicates direct comparison of the variation explained by each group. To partly correct for this problem, we used a measure of variation that included a downward adjustment for the number of predictor terms in a model; we reduced the variation explained by larger models by a larger amount relative to smaller models.

\section{Public health implications}

Past events cannot be changed, but they retain a minor influence on the perceived health of the persons who are now elderly in Barbados and elsewhere. Ongoing public health programs to reduce poverty and to improve access to health care, utilities, and education can be considered as long-term strategies to improve the health of those who will be elderly in the future. Current SEIs influence selfreported health status, and so interventions to support vulnerable groups in society (such as those living with limited means or with poor access to social support) could promote increased well-being among the elderly. In this study we considered four lifestyle risk factors of health status: obesity (measured using BMI and waist circumference), nutrition, exercise, and smoking. Education programs targeting these lifestyle determinants of health status represent a potentially cost-effective intervention to improve health among the elderly. Despite our surprising finding for female smokers, education programs targeted at the elderly should promote the health benefits of weight reduction among the overweight and obese as well as of good nutrition, exercise, and quitting smoking. Current disease was the overwhelming predictor of self-reported health in our study. The reactive strategy of targeting the sick with clinical care, along with aggressive promotion of lifestyle risk-factor reduction, could lessen the likelihood of disease progression and thus improve health status. Interventions in these four lifestyle-risk areas are complementary, and it will be important to understand the relative costs and benefits of each approach before decisions can be made on the allocation of funding. 
TABLE 10. The joint influence of prediction groups on self-reported health status among 1147 Barbadian participants, using variation explained (\%) by each model in study of historical and current predictors of self-reported health status, Barbados, 1999-2000

\begin{tabular}{|c|c|c|c|}
\hline \multirow[b]{2}{*}{ Model $^{\mathrm{a}}$} & \multicolumn{3}{|c|}{ Variation explained (\%) } \\
\hline & $\begin{array}{c}\text { Model } \\
\text { variation }\end{array}$ & $\begin{array}{l}\text { Common } \\
\text { variation }^{c}\end{array}$ & $\begin{array}{l}\text { Historical } \\
\text { variation }^{\mathrm{d}}\end{array}$ \\
\hline \multicolumn{4}{|l|}{ Single predictor group } \\
\hline Historical & 5.2 & - & 5.2 \\
\hline Current & 4.1 & - & 4.1 \\
\hline Lifestyle & 7.1 & - & 7.1 \\
\hline Disease & 33.6 & - & 33.6 \\
\hline \multicolumn{4}{|l|}{ Multiple predictor groups } \\
\hline Historical + Current & 7.9 & 1.4 & 3.8 \\
\hline Historical + Lifestyle & 11.2 & 1.1 & 4.0 \\
\hline Historical + Disease & 36.2 & 3.0 & 2.7 \\
\hline Historical + Current + Lifestyle & 13.7 & 2.7 & 2.9 \\
\hline Historical + Current + Disease & 36.9 & 6.4 & 2.4 \\
\hline Historical + Lifestyle + Disease & 37.6 & 8.7 & 2.4 \\
\hline Historical + Current + Lifestyle + Disease & 38.2 & 12.2 & 2.0 \\
\hline
\end{tabular}

${ }^{a}$ All models adjusted for age and gender.

b "Model variation" reports the variation explained by all predictor groups in the model, after adjusting for age and sex.

c "Common variation" reports the difference in variation between single predictor group models and those models containing more than one predictor group, and is interpreted as the variation that can be jointly ascribed to all predictor groups in the model.

$d$ "Historical variation" is the variation explained by historical predictor group alone, after all other terms in the model have been added.

\section{Summary}

Ultimately, the question for policymakers is whether a healthy and active old age is a realistic goal in Barbados and elsewhere. It is accepted that aging per se does not affect health (36). Although we all expect some level of functional decline as we age, a goal is to promote the separation of the perceived association between age and ill- health. As at any age, the elderly with better health habits can live healthily and actively for longer.

In influencing the health of the elderly, the compressed profile of morbidity has been reported in developed countries (37), with markers of aging developing later in life. These successes have been attributed to disease postponement or improved disease management, and they reflect the dual benefits of medical advances and public health advances.

In this study we have shown that for our study participants in Barbados, historical SEIs explain only a small proportion of variation in selfreported health status, and over half of that variation is mediated through current experience. The fact that current experience dominates our health perceptions means that these perceptions are conducive to adaptation through public health programs. Based on our results, we have suggested several broad routes for public health intervention. More comprehensive guidelines for programs to support active aging are available (38). Detailed data from the Americas are only recently available, and the SABE project is well placed to provide important guidance for public health policymakers. To maximize the use of these data, we must also consider the particular features of modeling cross-sectional data in the elderly.

Acknowledgements. Funding was provided by the Caribbean Development Bank, the Chronic Disease Research Centre Appeal Fund, the Pan American Health Organization, and the Caribbean Health Research Council. We acknowledge the support of the project coordinator, Ms. P. Howard, and our research staff who conducted interviews.

\section{REFERENCES}

1. United Nations. Report of the Second World Assembly on Ageing. New York: U.N.; 2002.

2. Palloni A, Pinto-Aguirre G, Pelaez M. Demographic and health conditions of aging in Latin America and the Caribbean. Int J Epidemiol. 2002;31:762-71.

3. Kalache A, Keller I. The greying world. A challenge for the twenty-first century. Sci Prog. 2000;83(1):33-54.

4. World Health Organization. Active ageing: a policy framework. Geneva: WHO; 2002. (WHO/NMH/NPH/02.8).

5. World Health Organization. Ottawa Charter on Health Promotion. Copenhagen: WHO Regional Office for Europe; 1986.

6. Moss C. Selection of topics and questions for the 2001 census. Popul Trends. 1999;97(9):28-36.
7. Miilunpalo S, Vuori I, Oja P, Pasanen M, Urponen $\mathrm{H}$. Self-rated health status as a health measure: the predictive value of self-reported health status on the use of physician services and on mortality in the working-age population. J Clin Epidemiol. 1997;50(5):517-28.

8. McLeod CB, Lavis JN, Mustard CA, Stoddart GL. Income inequality, household income, and health status in Canada: a prospective cohort study. Am J Public Health. 2003;93(8): 1287-93.

9. Borrell C, Muntaner C, Benach J, Artazcoz L. Social class and self-reported health status among men and women: what is the role of work organisation, household material standards and household labour? Soc Sci Med. 2004;58(10):1869-87.
10. Jones DJ, Beach SR, Forehand R, Foster SE Self-reported health in HIV-positive African American women: the role of family stress and depressive symptoms. J Behav Med. 2003; 26(6):577-99.

11. Wannamethee G, Shaper AG. Self-assessment of health status and mortality in middleaged British men. Int J Epidemiol. 1991;20: 239-45.

12. McGee DL, Liao Y, Cao G, Cooper RS. Selfreported health status and mortality in a multiethnic US cohort. Am J Epidemiol. 1999;149: 41-6.

13. Goldberg P, Guéguen A, Schmaus A, Nakache J-P, Goldberg M. Longitudinal study of associations between perceived health status and self reported diseases in the French 
Gazel cohort. J Epidemiol Community Health. 2001;55:233-8.

14. Palloni A. SABE Project. Protocol of the multicenter study: Health, Well-being and Aging in Latin America and the Caribbean. Washington, D.C.: Pan American Health Organization; 1999.

15. Regidor E, Banegas JR, Gutiérrez-Fisac JL, Domínguez V, Rodríguez-Artalejo F. Socioeconomic position in childhood and cardiovascular risk factors in older Spanish people. Int J Epidemiol. 2004;33:1-8.

16. Kaplan GA, Salonen J. Socioeconomic conditions in childhood and ischaemic heart disease during middle age. Br Med J. 1990;301: 1121-3.

17. Davey Smith G, Hart C, Blane D, Hole DJ. Adverse socioeconomic conditions in childhood and cause specific adult mortality: prospective observational study. Br Med J. 1998; 316:1631-5.

18. Von dem Knesebeck O, Luschen G, Cockerham WC, Siegrist J. Socioeconomic status and health among the aged in the United States and Germany: a comparative cross-sectional study. Soc Sci Med. 2003;57(9):1643-52.

19. Kaufman JS, Kaufman S, Poole C. Causal inference from randomized trials in social epidemiology. Soc Sci Med. 2003;57(12): 23972409.

20. Liberatos P, Link BG, Kelsey JL. The measurement of social class in epidemiology. Epidemiol Rev. 1988;10:87-121.

21. Lahelma E, Martikainen P, Laaksonen M, Aittomaki A. Pathways between socioeconomic determinants of health. J Epidemiol Community Health. 2003;58:327-32.
22. Peláez M, Palloni A, Albala C, Alfonso JC, Ham-Chande R, Hennis A, et al. Survey on Aging, Health and Wellbeing, 2000: Washington, D.C.: Pan American Health Organization; 2003.

23. Litwin H. Social network type and health status in a national sample of elderly Israelis. Soc Sci Med. 1998;46(4-5):599-609.

24. Lahuerta C, Borrell C, Rodríguez-Sanz M, Pérez K, Nebot M. La influencia de la red social en la salud mental de la población anciana. Gac Sanit. 2004;18(2):83-91.

25. Joint WHO/FAO Expert Consultation on Diet, Nutrition and the Prevention of Chronic Diseases. Diet, nutrition and the prevention of chronic diseases: report of a joint WHO/FAO expert consultation, 28 January-1 February, 2002. Geneva: World Health Organization; 2002. (WHO technical report series 916).

26. United States, National Institutes of Health. Clinical guidelines on the identification, evaluation, and treatment of overweight and obesity in adults. Bethesda: NIH; 1998. (NIH Publication No. 98-4083).

27. Sheikh JI, Yesavage JA. Geriatric Depression Scale (GDS): recent evidence and development of a shorter version. In: Brink TL, ed. Clinical gerontology: a guide to assessment and intervention. New York: The Haworth Press; 1986. Pp. 165-73.

28. StataCorp. Stata Statistical Software: release 8.0. College Station: StataCorp; 2003.

29. Little RJA, Rubin DB. Statistical analysis with missing data. New York: John Wiley \& Sons; 1987.

30. World Bank. World development indicators database [Web site]. Available from: http://
devdata.worldbank.org/external/CPProfile. asp? SelectedCountry $=\mathrm{BRB} \& \mathrm{CCODE}=\mathrm{BRB} \&$ CNAME $=$ Barbados\&PTYPE $=C P$. Accessed 25 May 2004.

31. Hay DI. Socioeconomic status and health status: a study of males in the Canada Health Survey. Soc Sci Med. 1988;27:1317-25.

32. House JS, Kessler RC, Herzog AR, Kinney AM, Mero RP, Breslow MF. Age, socioeconomic status, and health. Milbank Q. 1990;68: 383-411.

33. Rogers RG. Living and dying in the USA: sociodemographic determinants of death among Blacks and Whites. Demography. 1992;29:287-303.

34. Rowe JW, Kahn RL. Successful aging. Gerontologist. 1997;37:433-40.

35. Strawbridge WJ, Wallhagen MI, Cohen RD. Successful aging and well-being: self-rated compared with Rowe and Kahn. Gerontologist. 2002;42:727-33.

36. McMurdo MET. A healthy old age: realistic or futile goal? Br Med J. 2003;321:1149-51.

37. Kalache A, Aboderin I, Hoskins I. Compression of morbidity and active ageing: key priorities for public health policy in the 21st century. Bull World Health Organ. 2002;80(3):243-4.

38. Pan American Health Organization. Plan of action on health and aging: older adults in the Americas 1999-2002. Washington, D.C. PAHO; 1999 .

Manuscript received 29 June 2004. Accepted for publication 1 December 2004
RESUMEN

\section{Sucesos del pasado y del presente que determinan el estado de salud, según autonotificación, de las personas de edad en Barbados}

Palabras clave
Objetivo. Determinar la contribución relativa de sucesos del pasado y experiencias del presente al estado de salud de las personas de edad en Barbados, a fin de idear intervenciones sanitarias oportunas para esa población.

Métodos. La información usada para este estudio de prevalencia se recogió en Barbados entre diciembre de 1999 y junio de 2000 como parte del "proyecto SABE," encuesta multicéntrica efectuada en siete centros urbanos de América Latina y el Caribe para evaluar los factores que inciden en la salud y el bienestar de las personas de edad (de 60 años o más). Mediante regresión logística para datos ordinales se modelaron los factores que inciden en el estado de salud autonotificado, y también se evaluó la contribución relativa de algunos indicadores socioeconómicos del pasado, así como la de tres grupos de factores modificables, relativos al momento presente, con valor pronóstico - indicadores de situación socioeconómica, factores de riesgo asociados con el estilo de vida e indicadores de enfermedadusando medidas sencillas para calcular el grado de asociación y el ajuste del modelo.

Resultados. Los sucesos del pasado que tuvieron un efecto determinante sobre la salud explicaron $5,2 \%$ de la variación del estado de salud autonotificado, cifra que se redujo a $2,0 \%$ cuando se tuvo en cuenta la mediación de experiencias del presente. Los indicadores de la situación socioeconómica actual explicaron $4,1 \%$ de la variación en el estado de salud autonotificado; los factores de riesgo relacionados con el estilo de vida explicaron $7,1 \%, y$ los indicadores de enfermedad actual, $33,5 \%$.

Conclusiones. Las experiencias pasadas de orden socioeconómico influyeron sobre el estado de salud autonotificado por ancianos barbadenses. Más de la mitad de la influencia ejercida por sucesos pasados se vio mediada por experiencias del presente relacionadas con la situación socioeconómica, el estilo de vida y la presencia de enfermedades. El cuidado de los enfermos y la reducción de los factores de riesgo relacionados con el estilo de vida son aspectos de importancia que deben tenerse presentes al prestarles apoyo a las personas que son ancianas en la actualidad. Además, los programas que están en marcha ahora para reducir la pobreza y aumentar el acceso a la atención de salud y a la educación deben considerarse estrategias de largo plazo orientadas a mejorar la salud de los ancianos del futuro.

Estado de salud, anciano, factores socioeconómicos, Barbados. 